\title{
IDENTIFIKASI FAKTOR-FAKTOR YANG MEMENGARUHI REMAJA BERMAIN ROLE PLAYING GAME PADA SMARTPHONE
}

\author{
I Gede Ary Suartama ${ }^{1 \S}$, Ni Luh Putu Suciptawati ${ }^{2}$, Ni Made Asih ${ }^{3}$
}

\begin{abstract}
${ }^{1}$ Program Studi Matematika, Fakultas MIPA - Universitas Udayana [Email: Sayaterpevo0@gmail.com] ${ }^{2}$ Program Studi Matematika, Fakultas MIPA - Universitas Udayana [Email: Suciptawati@unud.ac.id] ${ }^{3}$ Program Studi Matematika, Fakultas MIPA - Universitas Udayana [Email: madeasih@unud.ac.id]

${ }^{\S}$ Corresponding Author
\end{abstract}

\begin{abstract}
This research is aimed to determine the factors that influence teenagers playing Role Playing games $(R P G)$ games using factor analysis. Sample of this study were 120 respondents. The respondents were teenager aged 16 years to 24 years who like to play RPG games. The data were obtained from primary sources using questionnaires distributed using Google form. The results showed there were three factors that influence teenagers playing RPG games. Those factors are: 1)The interest and satisfaction when playing the game, 2) Quality of the smartphone and friends, and 3) The quality of internet. The cumulative percentage of the three factors is able to explain $67.34 \%$ of the total variable.
\end{abstract}

Keywords : factor analysis, principal components analysis, role playing games

\section{PENDAhUluan}

Perkembangan smartphone sudah sangat luas, dengan adanya smartphone seseorang dapat melakukan akses internet dimana saja dan kapan saja. Teknologi smartphone yang semakin pesat juga menyediakan aspek hiburan seperti game, game merupakan sebuah kegiatan yang mampu menghilangkan kebosanan saat bekerja atau untuk bersenang-senang bersama orang lain. Pada awalnya game diciptakan untuk anak-anak, tetapi seiring perkembangan jaman game juga bisa disukai oleh orang dewasa.

Perkembangan game yang semakin pesat membuat para pengembang industri game berlomba-lomba untuk menciptakan berbagai genre game untuk memuaskan pengguna smartphone. Dengan perkembangan internet saat ini, semua permainan atau game di smartphone umumnya berbasis online, oleh karena itu dibutuhkan strategi yang tepat agar dapat bersaing dengan industri lainnya. Industri game diharapkan mengetahui faktor-faktor yang menyebabkan masyarakat lebih memilih genre game yang bervariasi. Memanfaatkan informasi yang tepat terkait dengan faktor yang menyebabkan masyarakat lebih memilih genre game maka industri game dapat membuat sebuah game yang sesuai dengan keinginan orang banyak.
Penelitian terdahulu mengenai game online cenderung berkaitan dengan minat pengguna dalam memainkan game online dilakukan oleh Pratiwi (2014) menunjukkan bahwa niat untuk bermain game online penggunanya hanya dipengaruhi oleh kepercayaan terhadap website game online dan norma subjektif yang berpengaruh secara signifikan terhadap niat bermain penggunanya. Penelitian tentang game online juga dilakukan oleh Rina (2017), dengan penelitiannya yang lebih menekankan terhadap minat pembelian item dalam game online dengan hasil bahwa pembelian item dalam game dipengaruhi oleh kepercayaan konsumen terhadap penyedia layanan pembelian item dalam game. Adapun fokus dalam penelitian ini lebih kepada mengkaji faktor-faktor yang memengaruhi minat remaja dalam memainkan game online berjenis RPG pada smartphone.

Tujuan penelitian ini penulis ingin mengetahui faktor-faktor yang memengaruhi minat remaja dalam memilih genre game RPG smartphone dan mengetahui faktor yang dominan memengaruhi remaja dalam memilih genre game RPG pada smartphone. Metode yang digunakan pada penelitian ini yaitu analisis faktor. Penelitian menggunakan analisis faktor pernah dilakukan oleh Ratnasari et al (2015) dengan menganalisis perilaku masyarakat dalam memilih merek handphone menggunakan 
principal components analysis. pada penelitian ini analisis faktor digunakan untuk mendapatkan faktor-faktor yang memengaruhi remaja bermain Role Playing Game (RPG) pada smartphone.

\section{METODE PENELITIAN}

\section{Metode Pengumpulan Data}

Data yang digunakan dalam penelitian ini adalah data primer yang diperoleh dari penyebaran kuesioner dalam bentuk google form kepada responden remaja berusia 16 sampai 24 tahun yang aktif bermain game online dan memiliki media sosial. Periode pelaksanaan penelitian ini dimulai dari bulan November tahun 2018 dan dilaksanakan di media sosial seperti LINE, Whatsapp, dan Facebook

Pengambilan sampel pada penelitian ini dilakukan dengan cara Purposive Sampling yaitu teknik pengambilan sampel dimana pemilihan sampel dilakukan dengan pertimbangan subjektif tertentu berdasarkan beberapa karakteristik yang dimiliki sampel tersebut yaitu, orang yang sedang bermain game online pada smartphone yang berusia 16 sampai 24 tahun sebanyak 120 responden. Metode untuk penarikan sampelnya mengunakan metode snowball sampling yaitu metode penentuan sampel yang sumber data pada awalnya berjumlah sedikit tetapi lama-lama menjadi membesar (Rice, 2007). Pengujian validitas dan reliabilitas dari kuesioner dilakukan setelah 30 data terkumpul

\section{Metode Analisis Data}

Pendekatan kuantitatif digunakan untuk menganalisis data yang terkumpul sehingga faktor-faktor yang memengaruhi remaja bermain role playing game (RPG) dapat diidentifikasi. Metode analisis faktor bertipe Explanatory Factor Analysis (CFA) dipilih untuk mereduksi variabel yang diwakili oleh item-item penyusun kuesioner dan teknik Principal Components Analysis (PCA) digunakan untuk membentuk faktor. Menurut Johnson \& Wichern (1998) Principal Components Analysis adalah prosedur yang paling sederhana di dalam melakukan ekstraksi faktor. Metode ini membentuk kombinasi linier dari indikator yang diobservasi.

\section{HASIL DAN PEMBAHASAN}

\subsection{Uji Validitas dan Reliabilitas}

Merujuk pendapat Sugiyono (2008), sebuah variabel dikatakan valid digunakan sebagai refleksi suatu konsep jika nilai korelasinya dengan total variabel yang lain $\geq 0.30$ dan konsep yang diukur bisa dipercaya bila nilai Cronbach's Alpha $\geq 0.60$. validitas item dan reliabilitas kuesioner diuji dengan aplikasi SPSS 22. Hasil uji validitas dan reliabilitas diperlihatkan pada tabel 1 .

Tabel 1. Uji validitas dan reliabilitas

\begin{tabular}{|l|r|r|}
\hline & $\begin{array}{l}\text { Item Total } \\
\text { Correlation }\end{array}$ & $\begin{array}{l}\text { Cronbach's } \\
\text { Alpha if } \\
\text { Item deleted }\end{array}$ \\
\hline Niat Bermain Game & 0.749 & 0.945 \\
\hline Bermain Lebih Sering & 0.805 & 0.944 \\
\hline Tidak Niat Berhenti & 0.823 & 0.944 \\
\hline Terlalu Susah & 0.707 & 0.946 \\
\hline Frustasi & 0.142 & 0.951 \\
\hline Susah Bagi Waktu & 0.728 & 0.945 \\
\hline Internet Lambat & 0.394 & 0.95 \\
\hline Puas Fitur & 0.696 & 0.946 \\
\hline Puas Grafik & 0.494 & 0.949 \\
\hline Puas Selesai Main & 0.808 & 0.944 \\
\hline Puas Saat Menang & 0.790 & 0.944 \\
\hline Puas Bisa Lomba & 0.627 & 0.947 \\
\hline Kesenangan bermain & 0.861 & 0.943 \\
\hline Bermain Sama Teman & 0.645 & 0.947 \\
\hline Semangat Saat Event & 0.854 & 0.943 \\
\hline Kualitas Smartphone & 0.409 & 0.95 \\
\hline Diajak Teman & 0.622 & 0.947 \\
\hline Teman Bicara Game & 0.740 & 0.945 \\
\hline Teman Newbie & 0.472 & 0.949 \\
\hline Teman Baru & 0.849 & 0.943 \\
\hline Sumber: Data & &
\end{tabular}

Sumber : Data diolah 2019

Pada tabel 1 tampak dari seluruh variabel terdapat satu variabel yang tidak valid yaitu variabel frustasi karena nilai korelasinya $<0.3$ dengan nilai Cronbach's Alpha total sebesar 0.949. Jika variabel frustasi dihilangkan makan akan mengubah nilai Cronbach's Alpha dari 0.949 menjadi 0.951 sehingga variabel frustasi dapat dihilangkan.

\subsection{Analisis Faktor}

Memperhatikan dari 19 item pertanyaan kuesioner yang tersisa setelah indikator frustrasi dikeluarkan, reduksi dari 19 item menjadi faktor-faktor yang diwakilinya dilakukan dengan EFA melalui tahapan seperti penjelasan berikut (Hair et al, 2010):

\section{a. Uji Kelayakan Data}

Uji kelayakan data digunakan untuk melihat apakah data pada kuesioner layak diolah menggunakan analisis faktor. Uji kelayakan data ditentukan dengan melihat nilai Bartlett Test of Sphericity, Kaiser Meyer-Oikin (KMO), dan Measures of Sampling Adequacy (MSA) yang dicari pada masing-masing indikator. Nilai besaran yang harus dipenuhi menurut Johnson \& Wichern (1998) adalah nilai Bartlett Test of 
Sphericity dengan signifikansi $<0.05$, nilai KMO harus $\geq 0.5$ dan nilai MSA harus $\geq 0.5$.

Nilai KMO yang diperoleh dari seluruh variabel adalah 0.913, dimana nilai KMO tersebut sudah memenuhi syarat. Secara umum analisis faktor dapat digunakan pada seluruh variabel yang terbentuk. Nilai signifikansi dalam uji Bartllett $0.000<0.05$, maka disimpulkan korelasi antar variabel yang menjadi pembentuk faktor dapat diterangkan oleh variabel lainnya.

Langkah selanjutnya adalah melakukan uji MSA, menurut Johnson \& Wichern (1998) nilai MSA harus berada pada $\geq 0.5$, dalam penelitian ini kriteria MSA yang dipakai adalah $>0.6$. Uji MSA untuk semua variabel dapat dilihat pada tabel 2.

Tabel 2. Nilai MSA seluruh indikator

\begin{tabular}{|c|c|c|c|}
\hline Indikator & $\begin{array}{c}\text { Nilai } \\
\text { MSA }\end{array}$ & Indikator & Nilai MSA \\
\hline$X_{1}$ & 0.887 & $X_{12}$ & 0.953 \\
\hline$X_{2}$ & 0.966 & $X_{13}$ & 0.941 \\
\hline$X_{3}$ & 0.918 & $X_{14}$ & 0.868 \\
\hline$X_{4}$ & 0.883 & $X_{15}$ & 0.955 \\
\hline$X_{6}$ & 0.838 & $X_{16}$ & 0.741 \\
\hline$X_{7}$ & 0.820 & $X_{17}$ & 0.935 \\
\hline$X_{8}$ & 0.938 & $X_{18}$ & 0.843 \\
\hline$X_{9}$ & 0.893 & $X_{19}$ & 0.909 \\
\hline$X_{10}$ & 0.955 & $X_{20}$ & 0.950 \\
\hline$X_{11}$ & 0.968 & & \\
\hline
\end{tabular}

Sumber : Data Diolah 2019

Hasil dari uji MSA menyatakan bahwa setiap indikator memiliki nilai MSA $>0.60$ yang berarti setiap indikator memenuhi syarat MSA, sehingga proses analisis faktor dapat dilanjutkan.

\section{b. Penentuan Jumlah Faktor}

Faktor dengan nilai eigen lebih dari 1 merupakan faktor yang akan dipilih, semakin besar nilai eigen pada suatu faktor maka semakin baik faktor tersebut dalam mewakili sejumlah variabel. Dengan menggunakan metode principal components analysis, faktor dengan nilai eigen yang lebih dari satu dapat dilihat pada tabel 3 .

Tabel 3. Jumlah Faktor yang Terbentuk

\begin{tabular}{|l|r|r|r|}
\hline \multirow{2}{*}{ Factor } & \multicolumn{3}{|c|}{ Initial Eigenvalues } \\
\cline { 2 - 4 } & \multicolumn{1}{|c|}{ Total } & \multicolumn{1}{c|}{$\begin{array}{c}\text { V of } \\
\text { Variance }\end{array}$} & Cumulative \% \\
\hline 1 & 10.282 & 54.115 & 54.115 \\
2 & 1.363 & 7.175 & 61.290 \\
\hline 3 & 1.149 & 6.048 & 67.338 \\
\hline
\end{tabular}

Sumber: Data Diolah 2019
Pada tabel 3 dapat dilihat bahwa terdapat 3 faktor dengan persentase kumulatif $67.338 \%$ mampu menjelaskan faktor-faktor yang memengaruhi minat bermain Role Playing Game (RPG).

\section{c. Rotasi Faktor}

Dalam penelitian ini, analisis faktor dengan ekstraksi principal components analysis diperoleh 3 faktor yang memengaruhi minat remaja dalam bermain Role Playing Game (RPG). Faktor-faktor tersebut memiliki total 19 variabel. Ketiga faktor dalam metode ekstraksi principal components analysis ini masing masing diberikan nama sesuai dengan pengelompokkan hasil pada rotasi faktor. Hasil rotasi faktor varimax dapat dilihat pada tabel 4 . Pada variabel Puas Bisa Lomba ditunjukkan bahwa nilai loading sebesar 0.488 , berdasarkan ketentuan nilai loading menurut Hair et al (2010) dijelaskan bahwa untuk sampel sebesar 120 responden nilai loading yang disarankan adalah 0.50, sehingga variabel Puas Bisa Lomba tidak bisa masuk ke dalam faktor karena nilai loadingnya dibawah 0.5 .

\section{d. Interpretasi Faktor}

Interpretasi faktor dilakukan dengan cara mengelompokkan indikator yang memiliki faktor pembobot minimal 0.50 karena sampel yang digunakan pada penelitian ini adalah 120 responden. Variabel yang memiliki faktor pembobot kurang dari 0.50 akan dikeluarkan dari model. Berdasarkan tabel 4 dapat dilihat bahwa terdapat 18 variabel yang tersebar dalam 3 faktor dengan total ragam $67.338 \%$ berdasarkan tabel 3.

Berdasarkan hasil rotasi varimax dapat dilihat bahwa variabel-variabel pada masingmasing faktor yang memengaruhi remaja bermain Role Playing Game (RPG) membentuk 3 faktor, tiga faktor dalam penelitian ini masingmasing diberi nama baru sesuai dengan pengelompokkan variabel pada faktor tersebut.

Faktor pertama bernama faktor Niat bermain dan kepuasan saat bermain game RPG yang memiliki nilai eigen sebesar 10.282 dan dapat menjelaskan nilai ragam sebesar $54.115 \%$. Faktor ini terbentuk atas 13 variabel berdasarkan tabel 4. Indikator "Susah Bagi Waktu" adalah indikator yang memiliki faktor loading tertinggi dengan nilai 0.840 yang berarti bahwa faktor niat bermain dan kepuasan saat bermain game dipengaruhi oleh susahnya membagi waktu antara bermain game dan pekerjaan lainnya. 
Tabel 4. Hasil Rotasi faktor dengan Metode Varimax

\begin{tabular}{|l|r|l|r|l|r|}
\hline \multicolumn{2}{|c|}{ Faktor 1 } & \multicolumn{2}{c|}{ Faktor 2 } & \multicolumn{2}{c|}{ Faktor 3 } \\
\hline Variabel & $\begin{array}{l}\text { Nilai } \\
\text { Loading }\end{array}$ & Variabel & $\begin{array}{l}\text { Nilai } \\
\text { Loading }\end{array}$ & Variabel & $\begin{array}{l}\text { Nilai } \\
\text { Loading }\end{array}$ \\
\hline Susah Bagi Waktu & 0.840 & Kualitas Smartphone & 0.858 & Internet Lambat & 0.778 \\
\hline Teman Bicara Game & 0.827 & Bermain Sama Teman & 0.735 & Puas Grafik & 0.728 \\
\hline Niat Bermain Game & 0.812 & $\begin{array}{l}\text { Teman pemula Dalam } \\
\text { game }\end{array}$ & 0.588 & Puas Bisa Lomba & 0.488 \\
\hline Teman Baru & 0.799 & & & & \\
\hline Terlalu Susah & 0.770 & & & & \\
\hline Bermain Lebih Sering & 0.724 & & & & \\
\hline Kesenangan Saat Main & 0.707 & & & & \\
\hline Semangat Saat Event & 0.689 & & & & \\
\hline Tidak Niat Berhenti & 0.672 & & & & \\
\hline Puas Selesai Main & 0.653 & & & & \\
\hline Puas Saat Menang & 0.630 & & & & \\
\hline Diajak Teman & 0.609 & & & & \\
\hline Puas Fitur & 0.597 & & & & \\
\hline
\end{tabular}

Sumber : Data Diolah 2019

Faktor kedua bernama Kualitas Smartphone dan teman bermain yang memiliki nilai eigen sebesar 1.363 dan mampu menjelaskan nilai ragam sebesar $7.175 \%$. Faktor ini terbentuk atas 3 indikator dengan indikator "Kualitas Smartphone" memiliki nilai faktor loading terbesar dengan nilai 0.858. Hal ini berarti bahwa semakin bagus spesifikasi smartphone yang digunakan maka permainan game RPG akan lebih baik seperti tidak force closed dalam permainan dan grafik dalam game tidak mengecewakan.

Faktor ketiga bernama Kualitas layanan internet yang memiliki nilai eigen sebesar 1.149 dan dapat menjelaskan nilai ragam sebesar $6.048 \%$. Faktor ini terbentuk atas 2 indikator dengan indikator "kecepatan Internet" yang memiliki nilai faktor loading terbesar dengan nilai 0.778. Hal ini berarti bahwa koneksi internet memengaruhi seseorang saat bermain game RPG karena semakin lambat koneksi internet maka loading data pada game akan menjadi lama sehingga permainan akan terasa lebih lama dari biasanya

\section{SIMPULAN DAN SARAN}

\section{A. Simpulan Penelitian}

Penelitian tentang faktor-faktor yang memengaruhi remaja bermain RPG pada Smartphone menyimpulkan beberapa hal:
1. Terdapat 3 faktor yang teridentifikasi memengaruhi remaja bermain RPG Ketiga faktor hasil ekstraksi dari 19 variabel asal adalah: (a) Niat bermain dan kepuasan saat bermain game, (b) Kualitas Smartphone dan teman bermain, dan (c) Kualitas layanan internet

2. Niat bermain dan kepuasan saat bermain game merupakan faktor dominan yang memengaruhi remaja untuk bermain game RPG pada Smart phone. Kepuasan saat bermain game meliputi kesenangan saat bermain game dan semangat saat ada event dalam game.

\section{B. Saran}

Bagi penelitian selanjutnya, mengingat masih banyak indikator yang berpengaruh terhadap minat bermain role playing game (RPG) pada smart phone, maka hal itu dapat dijadikan pertimbangan untuk penelitian selanjutnya.

\section{DAFTAR PUSTAKA}

Johnson, N., \& Wichern. (1998). Applied Multivariate Statistical Analysis. PrenticeHall: Englewood Cliffs.

Hair, Joseph F., J, Black, W., J. Babin, B., \& E. Anderson, R. (2010). Multivariate Data Analysis seventh edition. New Jersey: Pearson Education. 
Ratnasari, S. A., Suciptawati, N. L., \& Tari Tastrawati, N. K. (2015). Analisis Perilaku Masyarakat Dalam Memilih Merek Handphone dengan Analisis Faktor. EJurnal Matematika Vol. 4 (3), 135-140.

Rice, J. A. (2007). Mathematical Statistics and Data Analysis. USA: Thomson Brook/Cole.

Pratiwi, E. D. (2014). Analisa Faktor-Faktor yang Memengaruhi Niat Bermain Game Online. Jurnal Pilar Nusa Mandiri Vol.X, No.2 September 2014, 181.

Rina, Y. (2017). Analisis perilaku pengguna dalam pembelian item virtual pada game online. Journal of Animation and Games Studies, Vol.3 No.1-April 2017, 7-11.

Sugiyono. (2008). Statistika Untuk Penelitian. Bandung : Alfabeta. 